\title{
Use of stepwise lactate kinetics-oriented hemodynamic therapy could improve the clinical outcomes of patients with sepsis- associated hyperlactatemia
}

Xiang Zhou' ${ }^{1}$, Dawei Liu ${ }^{1 *}$, Longxiang Su' ${ }^{1}$ Bo Yao ${ }^{2}$, Yun Long ${ }^{1}$, Xiaoting Wang ${ }^{1}$, Wenzhao Chai ${ }^{1}$, Na Cui ${ }^{1}$, Hao Wang ${ }^{1}$ and Xi Rui ${ }^{1}$

\begin{abstract}
Background: Setting lactate kinetics at $>30 \%$ might improve the clinical outcomes of patients with sepsisassociated hyperlactatemia. The aim of this study was to explore the outcome benefits of stepwise lactate kinetics vs central venous oxygen saturation $\left(\mathrm{SCvO}_{2}\right)$-oriented hemodynamic therapy at $6 \mathrm{~h}$ as the protocol goal during early resuscitation.

Methods: The relevant parameters and adverse events after different targets in 360 randomly assigned patients with sepsis-associated hyperlactatemia were recorded and compared.

Results: Heart rate (HR) at $48 \mathrm{~h}$ in the $\mathrm{ScvO}_{2}$ group was higher than in the lactate kinetics group (105 $\pm 19 \mathrm{bpm}$ vs $99 \pm 20 \mathrm{bpm}, P=0.040$ ). The liquid balance at $4 \mathrm{~h}, 12 \mathrm{~h}$, and $24 \mathrm{~h}$ in the lactate kinetics group was larger than in the $\mathrm{ScvO}_{2}$ group (1535 (1271-1778) $\mathrm{ml}$ vs $826(631-1219) \mathrm{ml}, P<0.001 ; 1688(1173-1923) \mathrm{ml} v 1277$ (962-1588) $\mathrm{ml}, P<0.001$; and 1510 (904-2087) $\mathrm{ml}$ vs $1236(740-1808) \mathrm{ml}, P=0.005)$, respectively. Mortality was higher in the $\mathrm{ScvO}_{2}$ group (27.9\% vs $18.3 \%, P=0.033$ ), but there was no significant difference between the two groups in the length of stay in the ICU or mechanical ventilation. In terms of new onset organ dysfunction, there was a significant difference between the two groups in total bilirubin at $48 \mathrm{~h}$ and $72 \mathrm{~h}$. Based on the 60-day survival curves, there was significantly more mortality in the $\mathrm{ScvO}_{2}$ group than in the lactate kinetics group $\left(X^{2}=4.133, P=0.042\right)$. In addition, fewer adverse events occurred in the lactate kinetics group.
\end{abstract}

Conclusions: Stepwise lactate kinetics-oriented hemodynamic therapy can reduce mortality in patients with sepsisassociated hyperlactatemia compared with $\mathrm{ScvO}_{2}$-oriented therapy.

Trial registration: National Institutes of Health Clinical Trials Registry, NCT02566460. Registered on 26 September 2015.

Keywords: Lactate kinetics, $\mathrm{S}_{\mathrm{CVO}}$, Sepsis, Septic shock, Hemodynamic therapy

\footnotetext{
* Correspondence: dwliu98@163.com

${ }^{1}$ Department of Critical Care Medicine, Peking Union Medical College

Hospital, Peking Union Medical College and Chinese Academy of Medical

Sciences, Beijing 100730, China

Full list of author information is available at the end of the article
} 


\section{Background}

Morbidity due to sepsis affects $56-91$ people per $100,000 /$ year, and the associated mortality remains at approximately $20 \%$ or even higher [1-3]. Early goal-directed therapy (EGDT) in the treatment of severe sepsis and septic shock strategies suggested by Rivers et al. in 2001 have had a far-reaching impact on the resuscitation of patients with severe sepsis or septic shock [4]. The EGDT strategies have been recognized and recommended by the Surviving Sepsis Campaign (SSC) since 2002 as the core concept of the SSC guidelines [5-7], with profound impacts on the behavior of physicians in critical care medicine worldwide.

However, recently, with the results of the ProCESS, ARISE and ProMISe trials having been published, clinicians have begun to doubt central venous oxygen saturation (ScvO2) as an important objective of EGDT during the resuscitation of patients with sepsis [8-10]. Lactate, as a product of the anaerobic metabolism of tissue, is considered closer to the real situation of poor tissue perfusion. In recent years, some studies have noted that lactate kinetics could predict the prognoses of patients with severe sepsis [11-15]. In an observational study Nguyen et al. reported that lactate kinetics of $10 \%$ might indicate a better prognosis in patients with sepsis, and that every $10 \%$ increase in lactate kinetics over $6 \mathrm{~h}$ could further reduce mortality [12].

The EMShockNet investigators performed a multicenter, randomized non-inferiority trial and demonstrated that there was no significant difference in mortality among patients with sepsis when they used lactate kinetics greater than $10 \%$ in $6 \mathrm{~h}$, compared with $\mathrm{ScvO}_{2} \geq 70 \%$ [14]. by Craig et al. found in a retrospective study that $36 \%$ lactate kinetics in $6 \mathrm{~h}$ could be used as a prognostic cutoff value [15]. We presumed that the reason why the superiority of lactate kinetics was not demonstrated might be that the target lactate kinetics was not set sufficiently high. Therefore, we set the target thresholds of lactate kinetics at $2 \mathrm{~h}$ up to $10 \%, 4 \mathrm{~h}$ up to $20 \%$, and $6 \mathrm{~h}$ up to at least $30 \%$, and we defined it as stepwise lactate kinetics-oriented hemodynamic therapy. We designed a single-center, randomized controlled study to assess stepwise lactate kinetics-oriented vs $\mathrm{ScvO}_{2}$-oriented hemodynamic therapy in early 6-h resuscitation among patients with sepsis-associated hyperlactatemia in terms of the benefits for outcome.

\section{Methods}

\section{Study design and patient enrollment}

The trial was performed in the Critical Care Department of Peking Union Medical College Hospital in China. Patients with sepsis-associated hyperlactatemia admitted to the hospital from January 2013 to December 2014 were enrolled. The research protocol was reviewed and approved by the Ethics Committee of Peking Union
Medical College Hospital (PUMCH-S616) and was registered in the U.S. National Institutes of Health Clinical Trials Registry (NCT 02566460).

Patients were assessed according to inclusion criteria, which required that the patients be older than 18 years of age with confirmed or presumed infection, that they met two or more criteria for systemic inflammatory response syndrome $[5-7,16]$ and that there was evidence of refractory hypotension or serum lactate greater than $4 \mathrm{mmol}$ per liter. Refractory hypotension was defined as systolic blood pressure below $90 \mathrm{~mm} \mathrm{Hg}$ or mean arterial pressure (MAP) below $65 \mathrm{~mm} \mathrm{Hg}$ after an intravenous fluid challenge of $20 \mathrm{ml}$ or more per kilogram of body weight. Patients had to be enrolled in the study within $2 \mathrm{~h}$ of the earliest detection of the inclusion criteria and within $1 \mathrm{~h}$ of arrival in the ICU.

Patients were excluded if they met any of the following criteria: age younger than 18 years, pregnancy, an acute cerebral vascular event (Glasgow coma score $<5$ ), acute myocardial infarction or acute coronary syndrome, massive pulmonary embolism, status asthmaticus, primary diagnosed cardiac dysrhythmia, contraindication to central venous catheterization, active gastrointestinal hemorrhage, massive intra-abdominal infective focus without drainage, severe bronchopleural fistula, seizure, receiving chemotherapy or immunosuppressive therapy, or in the end stage of a disease. Non-inferiority testing was adopted in this study. Based on $\mathrm{ScvO}_{2}$, the mortality rate was approximately $25 \%$, so $\alpha$ was set at $0.05,1-\beta$ was set at 0.9 , the non-inferiority value was 0.15 , and the calculated sample size was 175 in each group. Randomization was performed with the use of a random number table. All of the patients or their legally authorized representatives provided written informed consent.

\section{Treatment}

Eligible patients were randomly assigned in a 1:1 ratio to one of the two groups: the protocol-based lactate kinetics group or the protocol-based $\mathrm{ScvO}_{2}$ group. When these patients were admitted to the ICU, they were referred to a single critical care physician, who was assigned as the research investigator. Routine procedures for the treatment of shock in the ICU, such as intratracheal intubation and central venous catheterization with the tip of the catheter located in the superior vena cava, were performed. Central venous pressure (CVP) was measured continuously using a bedside monitor. Antibiotics were administered intravenously at the discretion of the attending clinician. After the baseline measurements, the patients were randomized into one of the two groups by opening an opaque, sealed envelope containing the randomization assignment.

Patients assigned to the $\mathrm{ScvO}_{2}$ group received chest or neck central venous catheterization capable of measuring 
continuous $\mathrm{ScvO}_{2}$ (Edwards Lifesciences, Irvine, CA, USA). Then, the patients were resuscitated following the EGDT protocol, which was used by Rivers et al. [4]. The protocol provides for sequential resuscitation to meet the thresholds of central venous pressure, followed by MAP and then $\mathrm{ScrO}_{2}$ within the first $6 \mathrm{~h}$ of ICU admission. First, either crystalloid or colloid could be administered to achieve a CVP of 8-12 mmHg. Second, if the MAP was below $65 \mathrm{~mm} \mathrm{Hg}$, norepinephrine was administered to maintain MAP $\geq 65 \mathrm{mmHg}$. If the MAP was above $90 \mathrm{~mm}$ $\mathrm{Hg}$, vasodilators were administered until it was $90 \mathrm{~mm} \mathrm{Hg}$ or lower. Finally, if $\mathrm{ScvO}_{2}$ was below $70 \%$, red blood cells were transfused to achieve a hematocrit of at least $30 \%$. If $\mathrm{ScvO}_{2}$ continued to be below $70 \%$, dobutamine was initiated and titrated in attempts to achieve $\mathrm{ScvO}_{2}$ of at least $70 \%$.

Patients assigned to the lactate kinetics group were treated according to the protocol of lactate kineticsoriented therapy within the first $6 \mathrm{~h}$ of ICU admission. All of the patients in this group also accepted with central venous catheterization to monitor CVP, but they did not have $\mathrm{ScvO} 2$ monitored. They had similarly targeted thresholds in CVP, followed by MAP. However, blood lactate in the lactate kinetics group was monitored at a minimum of 1-h intervals:

$$
\text { Lactate kinetics }=\frac{\left(\text { Lactate }_{\text {initial }}-\text { Lactate }_{\text {time }}\right)}{\text { Lactate }_{\text {initial }}} \times 100 \% \text {. }
$$

Lactate $_{\text {initial }}$ was the blood lactate level when the patients were included in the study; lactate time $_{\text {was }}$ blood lactate level measured at relevant time points. We set the target thresholds of lactate kinetics at $2 \mathrm{~h}$ up to $10 \%, 4 \mathrm{~h}$ up to $20 \%$, and $6 \mathrm{~h}$ up to at least $30 \%$. After the lactate kinetics group achieved the resuscitation goals of CVP and MAP, if the lactate kinetics rate had not reached the intended target at the corresponding time point, red blood cells were transfused to achieve a hematocrit of at least $30 \%$. If the lactate kinetics remained below the intended target at the corresponding time point after the hematocrit was at least 30\%, dobutamine was initiated and titrated, in an attempt to achieve the target value. Lactate measurements were performed on venous whole blood samples using a blood gas analyzer (ABL90 FLEX, Radomater Medical, Copenhagen, Denmark).

After the $6 \mathrm{~h}$ of early intervention, the two groups continued to be observed at $12,24,48$, and $72 \mathrm{~h}$, and using the same treatment strategies. In addition to the hemodynamic treatment mentioned, a series of sepsis treatments based on the 2012 SCC guidelines were performed, including eliminating the foci, using antibiotics early, providing low-dose glucocorticoids, and controlling blood sugar.
To ensure patient safety, the study allowed the physician in charge to decide to adjust the treatment of patients according to the clinical situation. For example, in the $\mathrm{ScvO}_{2}$ group, the doctor in charge could decide at some point to check the patient's lactate and calculate the lactate clearance rate. In the lactate kinetics group, physicians could also decide at some point to start $\mathrm{ScvO}_{2}$ monitoring. However, these patients had to meet the following conditions for at least one item: (1) systolic blood pressure (SBP) was difficult to maintain (SBP $<90 \mathrm{mmHg}$ ) or decreased urine output $(<0.5 \mathrm{ml} / \mathrm{kg}$ per h); (2) respiratory conditions continued to worsen (including respiratory rate, oxygen saturation or oxygen requirement), and arterial blood gas or mechanical ventilation conditions continued to deteriorate; or (3) consciousness continued to deteriorate. Once patients received the treatment of the other group, he or she was also considered to be included due to intention-to-treat selection.

\section{Outcome measurements}

After the patients' enrollment, case report forms (CRFs) were completed by the attending physicians according to the protocols. The primary endpoint was 60 -day mortality. The secondary end points were ICU and hospital length of stay, ventilator-free days, and newly emerging organ failure. Other end points included the number of protocol goals achieved, administered treatments, and protocol-related adverse events. The protocol-related data were collected at baseline, at each hour for $6 \mathrm{~h}$ and then at 24, 48, and $72 \mathrm{~h}$. All of the patients were followed up until 60 days. The protocol implementation and data collection stopped when the patients or their families wished to withdraw from the program or refused further treatment, or if the patient died.

\section{Statistical analysis}

The data were analyzed using intention-to-treat principles. The count data were analyzed using the chi-square test or Fisher's exact method; for measurement data, if the two sets of data did not follow a normal distribution, they were described by medians (interquartile ranges), and we used the Mann-Whitney $U$ test to compare the two groups. If they had a normal distribution, mean \pm standard deviation was used, and the independent sample $t$ test was adopted to compare the two groups. Sixty-day survival curves were plotted, and the mortality rates in both groups were analyzed using the Breslow survival test. All of the data analyses were performed using SAS software, version 9.2 (SAS Institute Inc., Cary, NC, USA).

\section{Results}

Baseline characteristics

Between January 2013 and December 2014, a total of 420 patients with sepsis met the inclusion criteria. 
Among these patients, 12 met the exclusion criterion, and 48 refused to participate in this study. Finally, 360 eligible patients were randomized into the lactate kinetics group $(n=180)$ and the $\mathrm{ScvO}_{2}$ group $(n=180)$. Among the 180 patients in the lactate kinetics group, an internal jugular or subclavian catheter could not be inserted in 2 patients, the original plan was not implemented in 7 patients during the trial, and 19 patients did not meet the planned target, despite the protocol having been strictly followed. Among the 180 patients in the $\mathrm{ScvO}_{2}$ group, a jugular or subclavian catheter could not be inserted in 1 patient, 5 patients did not have the original plan implemented, and 15 patients did not meet the original plan (Fig. 1).

There were no significant differences between the two groups in the baseline data. The sites of infection in the two groups all indicated that pulmonary infection (48.3\% vs $47.7 \%, P=0.916$ ), severity of illness (APACHE II score $18(14-30)$ vs 20 (14-31), $P=0.512)$, organ function (alanine aminotransferase (ALT), total bilirubin (TBIL), serum creatinine (SCr), and troponin (Tni)) and hemodynamic status (HR, MAP, CVP, lactate) did not differ significantly (Table 1 ).

\section{Treatment and vital signs}

Of the 180 patients in the $\mathrm{ScvO}_{2}$ group, 5 required other indicators, such as lactate, to guide the clinical intervention. Therefore, the original plan was not implemented in these patients. The 6-h $\mathrm{ScvO}_{2}$ compliance rate was 98.9\%. The average $\mathrm{ScvO}_{2}$ in the two groups was $77.7 \pm$ 9.5\%. Of the 180 patients in the lactate kinetics group, 7 required other indicators, such as $\mathrm{ScvO}_{2}$, to guide the clinical intervention. We recalculated the target achievement rate. The 2-h lactate kinetics target rate was met and the compliance rate above $10 \%$ was $83.9 \%$; the $4-h$ lactate kinetics rate was $87.2 \%$; and the 6 -h target rate was $80.6 \%$. The time course of $\mathrm{ScrO} 2$ in the $\mathrm{ScvO} 2$ group and lactate in the lactate kinetics group are shown as Additional file 1: Table S1.

There were no significant differences between the lactate kinetics and $\mathrm{ScvO}_{2}$ groups in the use of vasoactive drugs, inotropic drugs, or red blood cells. At $4 \mathrm{~h}, 12 \mathrm{~h}$, and $24 \mathrm{~h}$, more intravenous fluids were administered in the lactate kinetics group than in the $\mathrm{ScvO}_{2}$ group, with $1535(1271-1778) \mathrm{ml}$ vs $826(631-1219) \mathrm{ml}(P=0.000)$, $1688(1173-1923) \mathrm{ml}$ vs $1277(962-1588) \mathrm{ml}(P=0.000)$, and $1510(904-2087) \mathrm{ml}$ vs $1236(740-1808) \mathrm{ml}(P=$

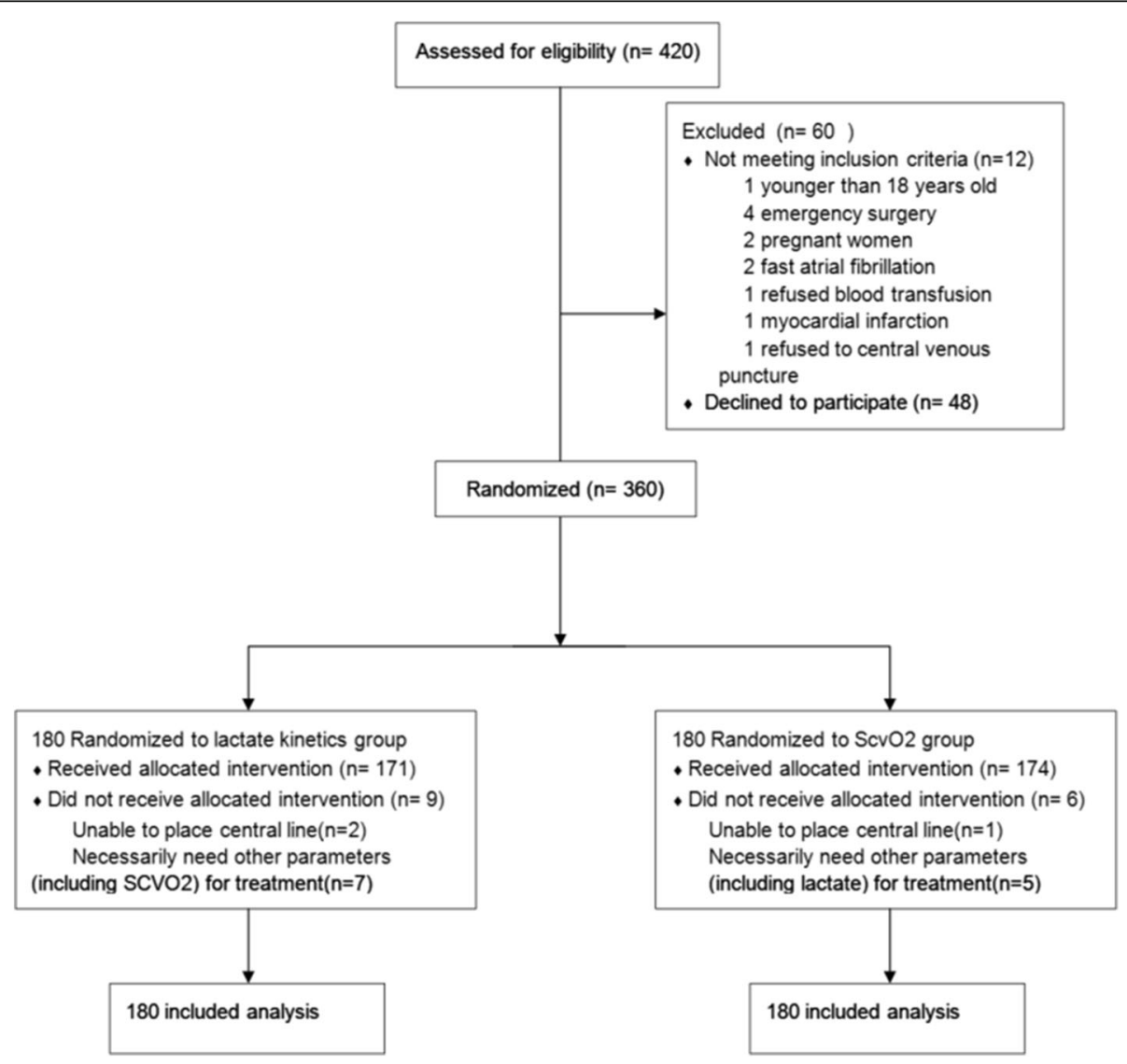

Fig. 1 The flowchart of the enrollment of this study. ScvO2 central venous oxygen saturation 
Table 1 The baseline data for patients with septic shock who were enrolled in this study

\begin{tabular}{|c|c|c|c|}
\hline & Lactate kinetics group & $\mathrm{ScvO}_{2}$ group & $P$ value \\
\hline & $n=180$ & $n=180$ & \\
\hline Sex, male/female, $n$ & $95 / 85$ & $106 / 74$ & 0.289 \\
\hline Age, years & $56(44-66)$ & $56(40-67)$ & 0.455 \\
\hline APACHE II score & $18(14-30)$ & $20(14-31)$ & 0.512 \\
\hline WBC counts, $\times 10 \wedge 9 / L$ & $12.9(8.4-17.9)$ & $12.0(8.4-17.3)$ & 0.957 \\
\hline Hemoglobin, g/L & $101(86-117)$ & $105(85-119)$ & 0.217 \\
\hline Platelets, $\times 10 \wedge 9 / L$ & $143(85-191)$ & $125(74-196)$ & 0.798 \\
\hline PT, s & $15.4(13.3-18.0)$ & $15.1(13.0-17.7)$ & 0.547 \\
\hline APTT, s & $36.2(28.8-51.9)$ & $35.6(29.4-51.1)$ & 0.519 \\
\hline$A L T, U / L$ & $106.0(53.5-156.5)$ & $78.0(46.0-142.0)$ & 0.161 \\
\hline TBIL, mmol/L & $19.5(11.6-37.2)$ & $18.1(10.7-41.9)$ & 0.807 \\
\hline Albumin, g/L & $27(22-30)$ & $27(23-31)$ & 0.109 \\
\hline $\mathrm{sCR}, \mathrm{mmol} / \mathrm{dL}$ & $91.5(65.3-163.5)$ & $102(65.5-182.5)$ & 0.484 \\
\hline cTnl, mg/L) & $0.42(0.04-3.40)$ & $0.29(0.05-2.97)$ & 0.635 \\
\hline $\mathrm{HR}$, bpm & $109 \pm 25$ & $114 \pm 28$ & 0.184 \\
\hline MAP, mmHg & $83(72-93)$ & $87(76-100)$ & 0.113 \\
\hline Arterial lactate, $\mathrm{mmol} / \mathrm{L}$ & $5.8(4.4-8.7)$ & $5.6(4.3-8.1)$ & 0.156 \\
\hline \multicolumn{4}{|l|}{ Site of infection } \\
\hline Lung, $n$ & 87 & 86 & 0.916 \\
\hline Intraperitoneal, $n$ & 58 & 60 & 0.822 \\
\hline Urinary system, $n$ & 1 & 1 & 1 \\
\hline Biliary tract infection, $n$ & 8 & 10 & 0.629 \\
\hline Skin and soft tissue, $n$ & 9 & 6 & 0.435 \\
\hline Blood infection, $n$ & 9 & 7 & 0.609 \\
\hline Other, $n$ & 8 & 10 & 0.629 \\
\hline
\end{tabular}

0.005), respectively (Table 2). There was no significant difference in the hemodynamic monitoring data for MAP, but $\mathrm{HR}$ in the $\mathrm{ScvO}_{2}$ group was higher at $48 \mathrm{~h}$ than in the lactate kinetics group $(105 \pm 19 \mathrm{bpm}$ vs $99 \pm$ $20 \mathrm{bpm}, P=0.040)$. CVP at $4 \mathrm{~h}, 6 \mathrm{~h}$, and $12 \mathrm{~h}$ was greater in the lactate kinetics group than in the $\mathrm{ScvO}_{2}$ group (8 (6-10) $\mathrm{mmHg}$ vs 7 (5-9) $\mathrm{mm} \mathrm{Hg}, P=0.039$; 9 (6-13) $\mathrm{mmHg}$ vs 8 (5-11) $\mathrm{mmHg}, P=0.027$; and 9 (7-11) $\mathrm{mmHg}$ vs $8(6-10) \mathrm{mmHg}, P=0.041$, respectively).

\section{Primary and secondary outcomes}

Sixty-day mortality was higher in the $\mathrm{ScvO}_{2}$ group than in the lactate kinetics group $(27.9 \%$ vs $18.3 \%, P=0.033)$, but there was no significant difference between the two groups in the duration of mechanical ventilation while on the ICU. In terms of new onset of organ dysfunction, there was no significant difference in impairment of renal function in the lactate kinetics group compared with the $\mathrm{ScvO}_{2}$ group. There were significant differences in TBIL between the two groups at $48 \mathrm{~h}$ and $72 \mathrm{~h}$ (Table 3). Based on the 60-day survival curves, mortality was greater in the $\mathrm{ScvO}_{2}$ group than in the lactate kinetics group, with significant differences after Breslow testing $\left(X^{2}=4.133, P=0.042\right)$ (Fig. 2).

\section{Adverse events}

Equal numbers of adverse events occurred in the two groups (Table 4). There were adverse events in four cases in the lactate kinetics group (2.2\%), while in the $\mathrm{ScvO}_{2}$ group there were adverse events in 5 cases $(2.8 \%)$. There was no statistically significant difference between the two groups $(P=1.000)$. Adverse events in the lactate kinetics group included one case of acute pulmonary edema, two cases of cardiac arrhythmia, and one case of catheter-related infections, while the adverse events in the $\mathrm{ScvO}_{2}$ group included one case of acute pulmonary edema, one case of acute myocardial infarction, and three cases of arrhythmia. 
Table 2 Interventions in the $\mathrm{ScvO}_{2}$-oriented group and lactate kinetics-oriented group during the treatment process

\begin{tabular}{|c|c|c|c|}
\hline & Lactate kinetics group & $\mathrm{ScvO}_{2}$ group & $P$ value \\
\hline & $n=180$ & $n=180$ & \\
\hline $\mathrm{RBC}$ volume at $24 \mathrm{~h}, \mathrm{ml}$ & $144 \pm 192$ & $152 \pm 193$ & 0.705 \\
\hline \multicolumn{4}{|l|}{ Norepinephrine, \% } \\
\hline 1st day & $46.1 \%(83 / 180)$ & $46.7 \%(84 / 180)$ & 0.916 \\
\hline 2nd day & $38.9 \%(70 / 180)$ & $40.6 \%(73 / 180)$ & 0.747 \\
\hline 3rd day & $27.2 \%(49 / 180)$ & $30.3 \%(54 / 180)$ & 0.560 \\
\hline \multicolumn{4}{|l|}{ Norepinephrine, $\mu \mathrm{g} / \mathrm{kg} / \mathrm{h}$} \\
\hline & $0(0-4.46)$ & $0(0-7.75)$ & 0.843 \\
\hline & $0(0-3.67)$ & $0(0-7.19)$ & 0.1 \\
\hline & $0(0-0.57)$ & $0(0-2.45)$ & 0.272 \\
\hline \multicolumn{4}{|l|}{ Dobutamine, \% } \\
\hline 1st day & $2.2 \%(4 / 180)$ & $3.9 \%(7 / 180)$ & 0.358 \\
\hline 2nd day & $4.4 \%(8 / 180)$ & $3.3 \%(6 / 180)$ & 0.586 \\
\hline 3rd day & $3.9 \%(7 / 180)$ & $3.3 \%(6 / 180)$ & 0.778 \\
\hline \multicolumn{4}{|l|}{ Dobutamine, $\mu \mathrm{g} / \mathrm{kg} / \mathrm{h}$} \\
\hline 1st day & $0(0-0)$ & $0(0-0)$ & 0.325 \\
\hline 2nd day & $0(0-0)$ & $0(0-0)$ & 0.263 \\
\hline 3rd day & $0(0-0)$ & $0(0-0)$ & 0.618 \\
\hline $\mathrm{CWH}$ & $26 / 154$ & $36 / 144$ & 0.163 \\
\hline \multicolumn{4}{|l|}{ Fluid volume, ml } \\
\hline $0-2 \mathrm{~h}$ & 563 (259-922) & $590(288-960)$ & 0.539 \\
\hline $2-4 \mathrm{~h}$ & 1535 (1271-1778) & $826(631-1219)$ & $<0.001$ \\
\hline $4-6 h$ & 1687 (1476-1929) & $1255(1008-1537)$ & 0.358 \\
\hline $6-12 \mathrm{~h}$ & 1688 (1173-1923) & $1277(962-1588)$ & $<0.001$ \\
\hline $12-24 \mathrm{~h}$ & $1510(904-2087)$ & $1236(740-1808)$ & 0.005 \\
\hline 24-48 h & $465(341-606)$ & $424(279-552)$ & 0.071 \\
\hline $48-72 \mathrm{~h}$ & $278(159-410)$ & $284(226-324)$ & 0.502 \\
\hline
\end{tabular}

$\mathrm{ScVO}_{2}$ central venous oxygen saturation, $\mathrm{CVVH}$ continuous veno-venous hemofiltration

\section{Discussion}

The main finding of this randomized, controlled trial was that stepwise lactate kinetics-oriented hemodynamic therapy could reduce mortality among patients with sepsis-associated hyperlactatemia, compared with $\mathrm{ScvO}_{2}$-oriented therapy. The therapeutic targets were reached in most patients during the first $6 \mathrm{~h}$, which could indicate that the protocols were easily accepted and implemented. The lactate kinetics group had more fluid within the first $24 \mathrm{~h}$, especially at $4 \mathrm{~h}, 12 \mathrm{~h}$, and $24 \mathrm{~h}$, but there were no differences between the two groups at $48 \mathrm{~h}$ or $72 \mathrm{~h}$. The lactate kinetics group had a lower heart rate and less norepinephrine than the $\mathrm{ScvO}_{2}$ group, especially at $48 \mathrm{~h}$. However, there was no difference in CVP between the two groups. More patients required dobutamine in the lactate kinetics group than in the $\mathrm{ScvO}_{2}$ group, but the difference was not significant.
In addition, there was no difference in adverse events between these two groups.

An optimal resuscitation strategy for sepsis patients should have two characteristics: (1) it should be able to generate sufficient driving force for the specific clinical treatment so that it can better guide the clinical therapy, and (2) it should also be able to achieve effective resuscitation while avoiding overtreatment. The strategy recommended by EGDT [4] and the SSC bundles [2] has two central points - CVP and MAP, respectively - and the end point is $\mathrm{ScvO}_{2}$. This strategy was very clear in outlining the clinical path of resuscitation in patients with sepsis, and it has been widely accepted and promoted over the past 10 years.

The IMPreSS study group demonstrated that compliance with SSC bundles was independently associated with improvements in hospital mortality among patients 
Table 3 Primary and secondary clinical outcomes in the $\mathrm{ScvO}_{2}$-oriented group and lactate kinetics-oriented group

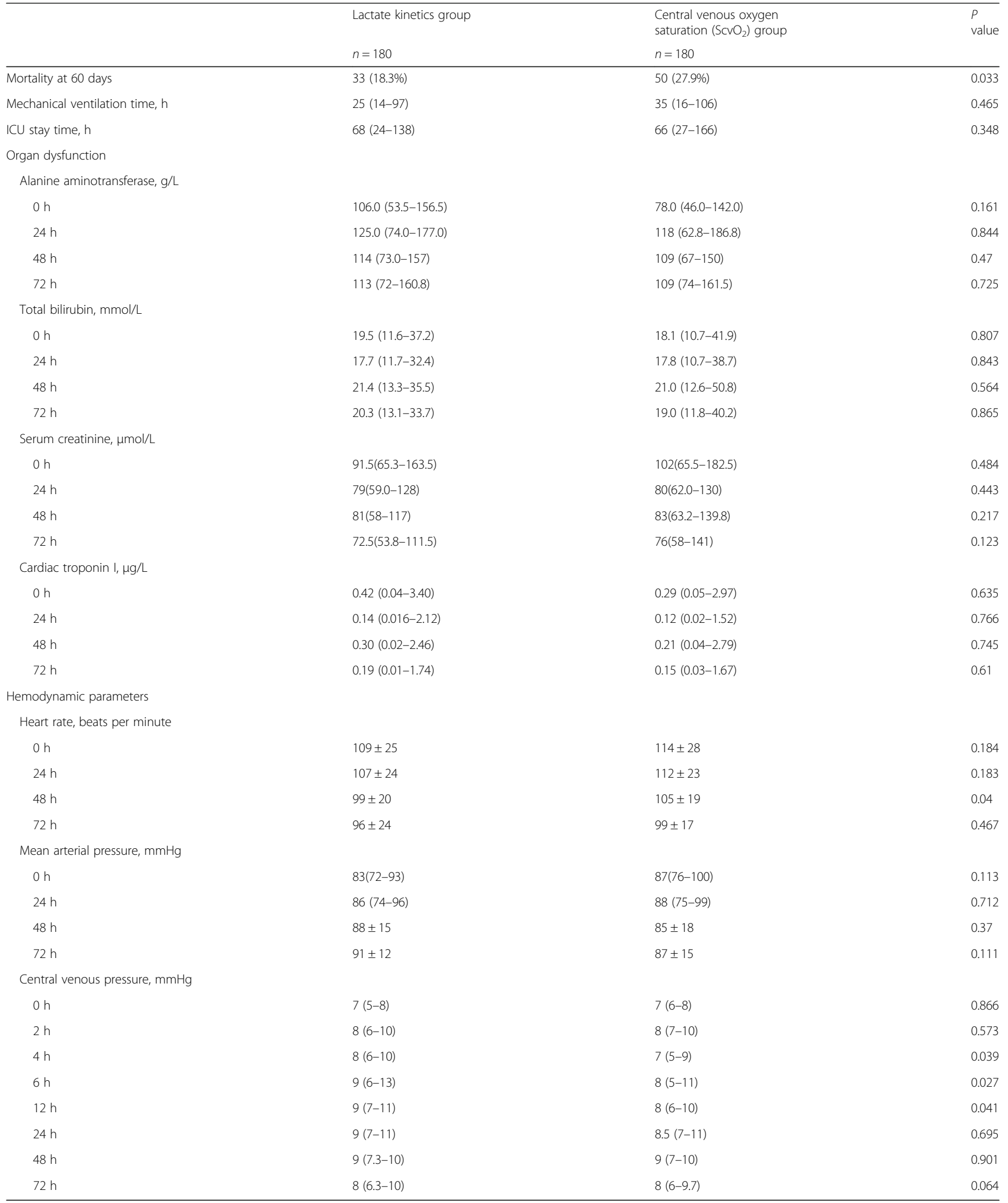

with sepsis [17]. Since ProCESS, ARISE, and ProMISe were published, the EGDT strategy in sepsis resuscitation has once again aroused great controversy [8-10].
All three of these studies demonstrated that protocols using $\mathrm{ScvO}_{2}$ as a resuscitation goal do not offer a survival advantage in patients with early septic shock. 


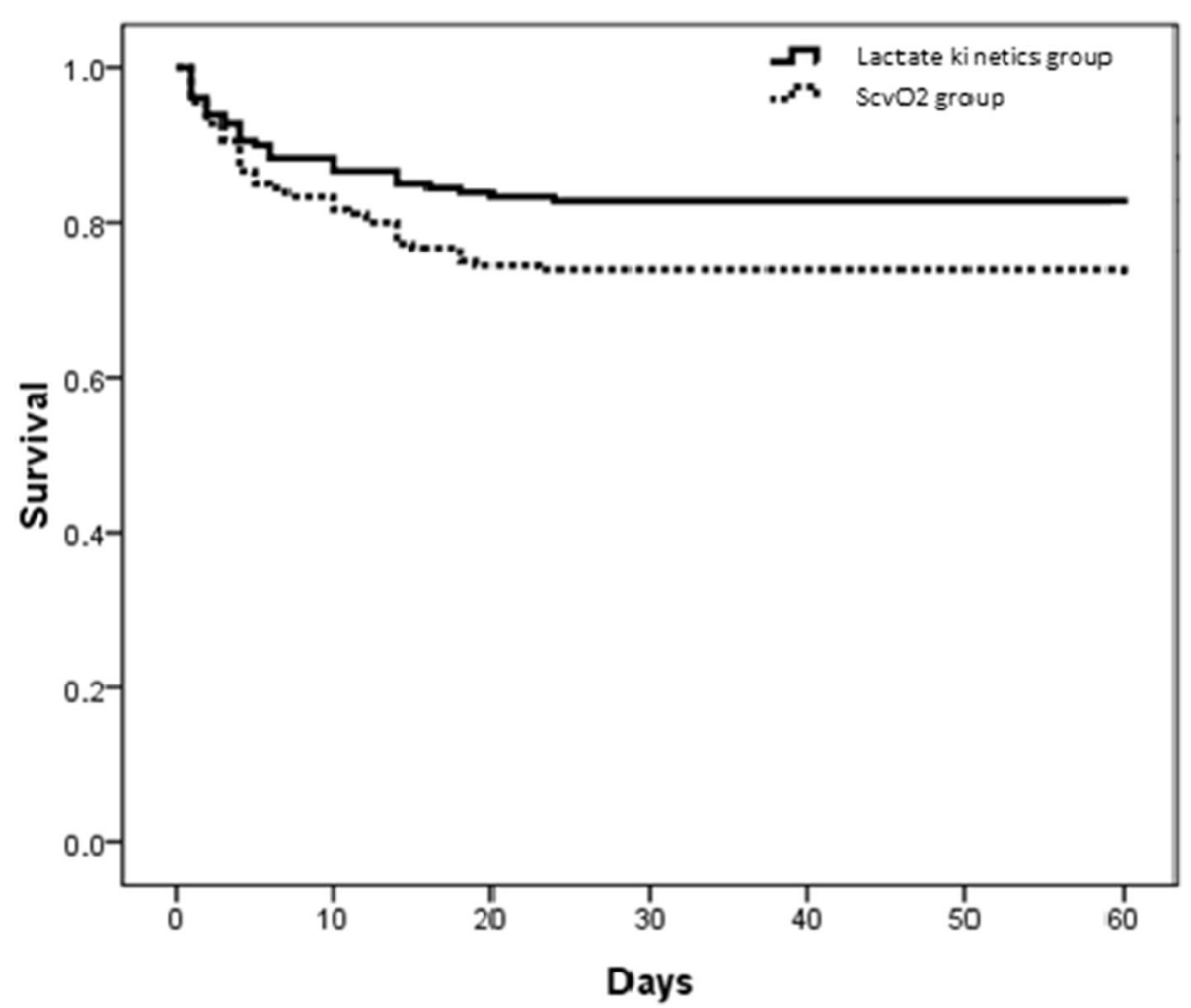

Fig. 2 The 60-day survival curves in the central venous oxygen saturation $\left(\mathrm{ScrO}_{2}\right)$-oriented group and lactate kinetics-oriented group

However, many researchers have assumed that the low mortality in the usual-care groups in the three studies might have been due to these patients receiving preexisting protocol-driven care, as outlined in the SSC bundles $[18,19]$. In fact, any treatment in clinical practice must have a clear goal to be reached. The core of the dispute is not the validity of goal-directed therapy

Table 4 The adverse event statistics in the $\mathrm{ScvO}_{2}$-oriented group and lactate kinetics-oriented group

\begin{tabular}{llll}
\hline & $\begin{array}{l}\text { Lactate } \\
\text { kinetics group } \\
n=180\end{array}$ & $\begin{array}{l}\mathrm{ScvO}_{2} \\
\text { group } \\
n=180\end{array}$ & $P$ value \\
\hline $\begin{array}{l}\text { Total number of adverse } \\
\text { events, } n / \%\end{array}$ & $4 / 2.2 \%$ & $5 / 2.8 \%$ & $>0.05$ \\
$\begin{array}{l}\text { Acute pulmonary edema, } n \\
\text { Acute myocardial infarction, } n\end{array}$ & 1 & 1 & \\
Arrhythmia, $n$ & 2 & 1 & \\
$\begin{array}{l}\text { Cardiac arrest, } n \\
\begin{array}{l}\text { Pneumothorax caused } \\
\text { by the puncture, } n\end{array} \\
\text { RBC allergy, } n\end{array}$ & 0 & 3 & \\
$\begin{array}{l}\text { Catheter-related } \\
\text { infections, } n\end{array}$ & 0 & 0 & \\
\hline
\end{tabular}

$\mathrm{ScVO}_{2}$ central venous oxygen saturation, $R B C$ red blood cells strategies but the question as to whether $\mathrm{ScvO}_{2}$ is the proper goal to guide early sepsis resuscitation.

The average enrollment $\mathrm{ScrO}_{2}$ levels, which were defined as the average levels when the patients were enrolled, were very different in the study of Rivers et al. compared to more recent studies, including our own. The average enrollment $\mathrm{ScvO}_{2}$ was $49 \%$ in the study of Rivers et al. However, the average enrollment $\mathrm{ScvO}_{2}$ levels in ProCESS, ARISE, and ProMISe were 71\%, $72.7 \%$, and $70 \%$, respectively, while in our study, it was $72.1 \%$ [8-10]. This discrepancy is one of the most important differences between the study of Rivers et al. and our study, indicating that there was quite a large proportion of patients in the $\mathrm{ScvO}_{2}$ group who could not receive future resuscitation according to the protocols in these studies (approximately 69\% of the patients in our study). In fact, Rivers et al. also reported that low $\mathrm{ScvO}_{2}$ usually indicates inadequate oxygen delivery or excessive oxygen consumption, but high $\mathrm{ScvO}_{2}$ did not exclude hypoperfusion in their study [4]. Pope and Textoris reported that not only did low $\mathrm{ScvO}_{2}$ suggest poor prognosis but that high $\mathrm{ScvO}_{2}$ was also associated with poor prognosis in patients with sepsis [20,21]. Thus, it could be that $\mathrm{ScvO}_{2}$-oriented therapy could not promote resuscitation in more than $50 \%$ of patients with sepsis and could not prevent overtreatment. 
It has been widely accepted that initial hyperlactacidemia is associated with greater mortality in patients with sepsis, and it has been regarded as independent of other organ failure indicators [11,22-25]. Lactate kinetics and its kinetics, which reflect the dynamic changes in blood lactate, might more accurately reflect the quality of shock resuscitation and could predict the prognosis of patients better than many other methods that consist purely of fixed measurements of hemodynamic parameters [11-14]. Therefore, we believe that lactate kinetics and its kinetics is a good endpoint of goal-directed therapy for resuscitation in patients with sepsis. However, the optimal cutoff value for lactate kinetics to guide resuscitation in sepsis is controversial. In clinical situations, any treatment to improve tissue perfusion (including increasing oxygen delivery $\left(\mathrm{DO}_{2}\right)$ or decreasing oxygen consumption $\left(\mathrm{VO}_{2}\right)$ ) can reduce blood lactate levels to a certain extent, that is, the inherent ability that reflects the effects of recovery during the resuscitation process. Therefore, an optimal lactate kinetics threshold must be sufficiently high to produce a driving force to propel the resuscitation strategy forward.

To date, lactate kinetics has been as the endpoint of goal-directed therapy in the resuscitation of patients with sepsis in three randomized, controlled clinical trials. The EMShockNet investigators reported non-inferiority in terms of reduction in hospital mortality among the group with lactate kinetics greater than $10 \%$ at $6 \mathrm{~h}$ and in the group with $\mathrm{ScvO}_{2} \geq 70 \%$ at $6 \mathrm{~h}(17 \%$ vs $23 \%)$ [15]. Jansen et al. reported that hospital mortality in the lactate kinetics group reaching $20 \%$ every $2 \mathrm{~h}$ was not different compared with the conventional treatment group $(33.9 \%$ vs $43.5 \%, P=0.067$ ) [24]. Tian et al. compared the results of 28-day mortality between lactate kinetics greater than, $10 \%$ and $30 \%$, respectively at $6 \mathrm{~h}$ and $\mathrm{ScvO}_{2}>70 \%$. The results were significantly lower in the $30 \%$ lactate kinetics group (28.6\%) and the $10 \%$ group (36.4\%) than in the $\mathrm{ScvO}_{2}$ group (63.2\%) $(P<$ $0.05)$ [25]. However, this study included only 62 cases, and 28-day mortality in the $\mathrm{ScvO}_{2}$ group was much higher than that in the present study $(63.2 \%$ ), while Craig et al. reported in a retrospective study that resuscitation within $6 \mathrm{~h}$ and lactate kinetics of 36\% could forecast the prognoses of patients with sepsis, and the cutoff value was set at $36 \%$ [14]. Therefore, in our goal-directed therapy protocol, after CVP and MAP reached the targets, based on the existing research results, the target lactate kinetics was set at $10 \%, 20 \%$, and $30 \%$ at $2 \mathrm{~h}, 4 \mathrm{~h}$, and $6 \mathrm{~h}$, respectively. This stepwise strategy resulted in more active therapy for patients with sepsis, especially in early fluid resuscitation.

Stepwise target setting lactate kinetics in our goaldirected therapy protocol could not only promote resuscitation, but it could also prevent overtreatment. As we know, despite full resuscitation, improvement in tissue perfusion requires a certain length of time. Lactate kinetics of $30 \%$ might be reasonable for early 6 -h resuscitation, but for a shorter time, such as 2 or $4 \mathrm{~h}$, it might be too high and could lead to overtreatment. Therefore, the targets of lactate kinetics were set at $10 \%, 20 \%$, and $30 \%$ at $2 \mathrm{~h}, 4 \mathrm{~h}$, and $6 \mathrm{~h}$, respectively, in our study to ensure that the targets could promote therapy during various stages of resuscitation and that overtreatment could be avoided at full steam. Serial blood lactate levels reflect both lactate production and clearance $[26,27]$. We could see that the lactate kinetics group achieved the more active therapy strategy, including more fluid infusion at $4 \mathrm{~h}, 12 \mathrm{~h}$ and $24 \mathrm{~h}$, but there were no significant differences in the CVP levels, the ratio of applications, or the dosage of vasoactive and inotropic drugs between the two groups. Furthermore, there was no significant difference in fluid balance at 48 and $72 \mathrm{~h}$ between the two groups.

There were several limitations to this study. First, it was a single-center study. A larger, more rigorous multicenter study could further confirm our conclusions in the future. Second, this study was a non-blinded, randomized, controlled study. Therefore, this study used a rigorous method of randomization, rigorous training and inspection procedures to ensure that compliance with each step was maintained at a relatively high level (greater than 90\%), thus minimizing the potential for errors. Third, this study explored only patients with definite diagnoses of sepsis, but patients with potential shock who were not diagnosed have not been studied. Early identification and resuscitation in these patients could also be a very critical topic in sepsis therapy. Fourth, there were significant differences between recent trials on EGDT and the Rivers trial. Patients were already resuscitated by some method (initial $\mathrm{ScvO}_{2}$ values or lactate values were comparable to those values after hours of therapy in the Rivers trial). The moment of starting resuscitation will have different impacts on outcome, and also importantly, the interpretation of several goals will be different.

\section{Conclusions}

In summary, stepwise lactate kinetics target-oriented therapy could reduce mortality among patients with sepsis, compared with $\mathrm{ScvO}_{2}$-oriented protocolized therapy $(\geq 70 \%)$. Lactate kinetics could become one of the indicators of resuscitation. However, it still requires large-scale and multicenter clinical studies to verify our findings.

\section{Additional file}

Additional file 1: Table S1. Time course of $\mathrm{ScvO} 2$ in the $\mathrm{ScvO} 2$ group and of lactate in the lactate kinetics group. (DOCX $13 \mathrm{~kb}$ ) 


\section{Abbreviations}

ALT: Alanine aminotransferase; CRF: Case report forms; CTnl: Cardiac troponin I; CVP: Central venous pressure; DO2: Oxygen delivery; EGDT: Early goaldirected therapy; HR: Heart rate; MAP: Mean arterial pressure; RBC: Red blood cells; SBP: systolic blood pressure; SCr: Serum creatinine; ScvO2: Central venous oxygen saturation; SSC: Surviving Sepsis Campaign; TBIL: Total bilirubin; Tni: Troponin; VO2: Oxygen consumption WBC, White blood cells

\section{Acknowledgements}

Not applicable.

\section{Funding}

This study was supported by a grant from National Health and Family Planning Commission of the People's Republic of China (Special Fund for Health Scientific Research in the Public Interest Program: number 201202011).

\section{Availability of data and materials}

Not applicable.

\section{Authors' contributions}

Conception and design: DL, XZ; patient treatment and collection of data: $\mathrm{YL}, \mathrm{XW}$, WC, NC, HW, XR; analysis and interpretation: $B Y, L S, X Z$; drafting of the manuscript for important intellectual content: $L S, X Z$; revision of the final manuscript: $D L, Y L$, XW, WC, NC, HW, XR. All authors read and approved the manuscript

\section{Competing interests}

The authors declare that they have no competing interests.

\section{Consent for publication}

Written informed consent was obtained from the patients for publication of their individual details in this manuscript. The consent form is in the patients' clinical notes and is available for review by the Editor-in-Chief. All authors consent to the manuscript being published in Critical Care.

\section{Ethical approval and consent to participate}

The research protocol was reviewed and approved by the Ethics Committee of Peking Union Medical College Hospital (PUMCH-S616) and was registered in the U.S. National Institutes of Health Clinical Trials Registry (NCT 02566460).

\section{Author details}

'Department of Critical Care Medicine, Peking Union Medical College Hospital, Peking Union Medical College and Chinese Academy of Medical Sciences, Beijing 100730, China. ${ }^{2}$ Department of Critical Care Medicine, The Affiliated Hospital of Qingdao University Medical College, Qingdao, Shandong Province 266000, China.

Received: 10 May 2016 Accepted: 24 January 2017

Published online: 16 February 2017

\section{References}

1. Jawad I, Luksic I, Rafnsson SB. Assessing available information on the burden of sepsis: global estimates of incidence, prevalence and mortality. J Glob Health. 2012;2(1):010404.

2. Levy MM, Artigas A, Phillips GS, Rhodes A, Beale R, Osborn T, Vincent JL, Townsend S, Lemeshow S, Dellinger RP. Outcomes of the Surviving Sepsis Campaign in intensive care units in the USA and Europe: a prospective cohort study. Lancet Infect Dis. 2012;12(12):919-24.

3. Cuthbertson BH, Elders A, Hall S, Taylor J, MacLennan G, Mackirdy F, Mackenzie SJ, Scottish Critical Care Trials Group, Scottish Intensive Care Society Audit Group. Mortality and quality of life in the five years after severe sepsis. Crit Care. 2013;17(2):R70.

4. Rivers E, Nguyen B, Havstad S, Ressler J, Muzzin A, Knoblich B, Peterson E, Tomlanovich M, Early Goal-Directed Therapy Collaborative Group. Early goal-directed therapy in the treatment of severe sepsis and septic shock. N Engl J Med. 2001;345(19):1368-77.

5. Dellinger RP, Carlet JM, Masur H, Gerlach H, Calandra T, Cohen J, GeaBanacloche J, Keh D, Marshall JC, Parker MM, et al. Surviving Sepsis Campaign guidelines for management of severe sepsis and septic shock. Crit Care Med. 2004;32(3):858-73.

6. Dellinger RP, Levy MM, Carlet JM, Bion J, Parker MM, Jaeschke R, Reinhart $\mathrm{K}$, Angus DC, Brun-Buisson C, Beale R, et al. Surviving Sepsis Campaign: international guidelines for management of severe sepsis and septic shock: 2008. Crit Care Med. 2008:36(1):296-327.

7. Dellinger RP, Levy MM, Rhodes A, Annane D, Gerlach H, Opal SM, Sevransky JE, Sprung CL, Douglas IS, Jaeschke R, et al. Surviving Sepsis Campaign: international guidelines for management of severe sepsis and septic shock, 2012. Intensive Care Med. 2013;39(2):165-228.

8. Pro Cl, Yealy DM, Kellum JA, Huang DT, Barnato AE, Weissfeld LA, Pike F, Terndrup T, Wang HE, Hou PC, et al. A randomized trial of protocol-based care for early septic shock. N Engl J Med. 2014;370(18):1683-93.

9. Investigators A, Group ACT, Peake SL, Delaney A, Bailey M, Bellomo R, Cameron PA, Cooper DJ, Higgins AM, Holdgate A, et al. Goal-directed resuscitation for patients with early septic shock. N Engl J Med. 2014;371(16):1496-506.

10. Mouncey PR, Osborn TM, Power GS, Harrison DA, Sadique MZ, Grieve RD, Jahan R, Harvey SE, Bell D, Bion JF, et al. Trial of early, goal-directed resuscitation for septic shock. N Engl J Med. 2015:372(14):1301-11.

11. Arnold RC, Shapiro NI, Jones AE, Schorr C, Pope J, Casner E, Parrillo JE, Dellinger RP, Trzeciak S, Emergency Medicine Shock Research Network (EMShockNet) Investigators. Multicenter study of early lactate kinetics as a determinant of survival in patients with presumed sepsis. Shock. 2009:32(1):35-9.

12. Nguyen $H B$, Rivers EP, Knoblich BP, Jacobsen G, Muzzin A, Ressler JA, Tomlanovich MC. Early lactate kinetics is associated with improved outcome in severe sepsis and septic shock. Crit Care Med. 2004;32(8):1637-42.

13. Puskarich MA, Trzeciak S, Shapiro NI, Arnold RC, Heffner AC, Kline JA, Jones AE, Emergency Medicine Shock Research Network (EMSHOCKNET). Prognostic value and agreement of achieving lactate kinetics or central venous oxygen saturation goals during early sepsis resuscitation. Acad Emerg Med. 2012;19(3):252-8.

14. Jones AE, Shapiro NI, Trzeciak S, Arnold RC, Claremont HA, Kline JA, Emergency Medicine Shock Research Network (EMShockNet) Investigators. Lactate kinetics vs central venous oxygen saturation as goals of early sepsis therapy: a randomized clinical trial. JAMA. 2010;303(8):739-46.

15. Walker CA, Griffith DM, Gray AJ, Datta D, Hay AW. Early lactate kinetics in septic patients with elevated lactate levels admitted from the emergency department to intensive care: time to aim higher? J Crit Care. 2013;28(5):832-7.

16. Bone RC, Balk RA, Cerra FB, Dellinger RP, Fein AM, Knaus WA, Schein RM Sibbald WJ. Definitions for sepsis and organ failure and guidelines for the use of innovative therapies in sepsis. The ACCP/SCCM Consensus Conference Committee. American College of Chest Physicians/Society of Critical Care Medicine. Chest. 1992;101(6):1644-55.

17. Rhodes A, Phillips G, Beale R, Cecconi M, Chiche JD, De Backer D, Divatia J, Du B, Evans $L$, Ferrer R, et al. The Surviving Sepsis Campaign bundles and outcome: results from the International Multicentre Prevalence Study on Sepsis (the IMPreSS study). Intensive Care Med. 2015;41(9):1620-8.

18. Coz YA. Protocol-based care for early septic shock. N Engl J Med. 2014:371(4): 384-5.

19. Manaktala S, Claypool SR. Early, goal-directed resuscitation for septic shock. N Engl J Med. 2015;373(6):577.

20. Pope JV, Jones AE, Gaieski DF, Arnold RC, Trzeciak S, Shapiro NI, Emergency Medicine Shock Research Network Investigators. Multicenter study of central venous oxygen saturation $(\mathrm{ScvO}(2))$ as a predictor of mortality in patients with sepsis. Ann Emerg Med. 2010;55(1):40-6. e41.

21. Textoris J, Fouche L, Wiramus S, Antonini F, Tho S, Martin C, Leone M. High central venous oxygen saturation in the latter stages of septic shock is associated with increased mortality. Crit Care. 2011;15(4):R176.

22. Bakker J, Coffernils M, Leon M, Gris P, Vincent JL. Blood lactate levels are superior to oxygen-derived variables in predicting outcome in human septic shock. Chest. 1991;99(4):956-62.

23. Mikkelsen ME, Miltiades AN, Gaieski DF, Goyal M, Fuchs BD, Shah CV, Bellamy $\mathrm{SL}$, Christie JD. Serum lactate is associated with mortality in severe sepsis independent of organ failure and shock. Crit Care Med. 2009;37(5):1670-7.

24. Jansen TC, van Bommel J, Schoonderbeek FJ, Sleeswijk Visser SJ, van der Klooster JM, Lima AP, Willemsen SP, Bakker J, Lactate Study Group. Early lactate-guided therapy in intensive care unit patients: a multicenter, open-label, randomized controlled trial. Am J Respir Crit Care Med. 2010;182(6):752-61.

25. Tian HH, Han SS, Lv CJ, Wang T, Li Z, Hao D, Shang QM, Wang XZ. The effect of early goal lactate kinetics rate on the outcome of septic shock patients with severe pneumonia. Zhongguo Wei Zhong Bing Ji Jiu Yi Xue. 2012;24(1):42-5.

26. Vincent JL. Serial blood lactate levels reflect both lactate production and clearance. Crit Care Med. 2015:43(6):e209.

27. Vincent JL. Lactic acidosis. N Engl J Med. 2015;372(11):1077-8. 